\title{
THE INFLUENCE OF THE CONDITIONS OF EMULSION MIST FORMATION ON THE SURFACE ROUGHNESS OF AISI 1045 STEEL AFTER FINISH TURNING
}

\author{
Eugene Feldshtein'1, Jerzy Józwik², Stanislaw Legutko³
}

1 Faculty of Mechanical Engineering, University of Zielona Gora, 4 Prof. Z. Szafrana Street, 65-516 Zielona Gora, Poland, e-mail: Eugene.Feldshtein@wp.pl

2 Department of Production Engineering, Mechanical Engineering Faculty, Lublin University of Technology, 36 Nadbystrzycka Street, 20-816 Lublin, Poland, e-mail: j.jozwik@pollub.pl

3 Faculty of Mechanical Engineering and Management, Poznan University of Technology, 3 Piotrowo Street, 60-965 Poznan, Poland, e-mail: stanislaw.legutko@put.poznan.pl

Received: 2016.04.15

Accepted: 2016.05.10

Published: 2016.06.01

\begin{abstract}
The processes of machining have vital influence on the operating properties of machine parts because they ensure the formation of the required geometrical structure of the working surfaces and the condition of the top layer. In this paper the influence of emulsion mist parameters on $\mathrm{Ra}, \mathrm{Rz}$ and $\mathrm{RSm}$ surface roughness parameters is described when finishing the turning of $\mathrm{C} 45$ carbon steel. It was found that cutting parameters have considerably greater influence on roughness parameters in comparison with emulsion mist conditions. When increasing cutting speed from 100 to $300 \mathrm{~m} / \mathrm{min}$ $\mathrm{Ra}$ and $\mathrm{Rz}$ values decrease nearly 2 times, but RSm value does not depend on speed. When increasing feed rate from 0.1 to $0.2 \mathrm{~mm} / \mathrm{rev} \mathrm{Ra}, \mathrm{Rz}$ and $\mathrm{RSm}$ values increase more than twice. Changes of emulsion mass flow and compressed air flow affect roughness parameters reach $9-15 \%$ of maximum. It was shown that Parameter Space Investigation method can be used efficiently for quick analysis of tested parameters and optimization of their values.
\end{abstract}

Keywords: surface roughness, turning, cutting parameters, emulsion mist.

\section{INTRODUCTION}

Processes of machining have vital influence on the operating properties of machine parts because they ensure the formation of the required geometrical structure of the working surfaces and the condition of the top layer. It is stated in literature that $70-80 \%$ of the total changes of surface wear resistance result from changes of roughness parameters of friction surfaces [4]. In the conditions of technically dry friction, the greatest influence is that of the vertical roughness parameters and the material contribution, while the horizontal parameters have more influence on the surface wear resistance under the conditions of boundary friction and in the presence of a lubricant [17]. Under such conditions, an increase of the Ra parameter by 30 times results in the friction coefficient increase by 2 times. The influence of roughness on the conditions of friction and wear have been discussed in $[10,11]$ for silicon, in [1] for ceramics, in [15] for pure metals, in [3] for carbon steel and titanium alloy and in $[14,18]$ for hardened steel. Broad analysis of the possibility of assessment and prediction of the functional properties of surfaces manufactured in various machining processes basing on the $2 \mathrm{D}$ and $3 \mathrm{D}$ surface roughness parameters can be found in [18].

Selecting adequate machining parameters, cutting edge angles, as well as introducing cooling and lubricating agents (most often ma- 


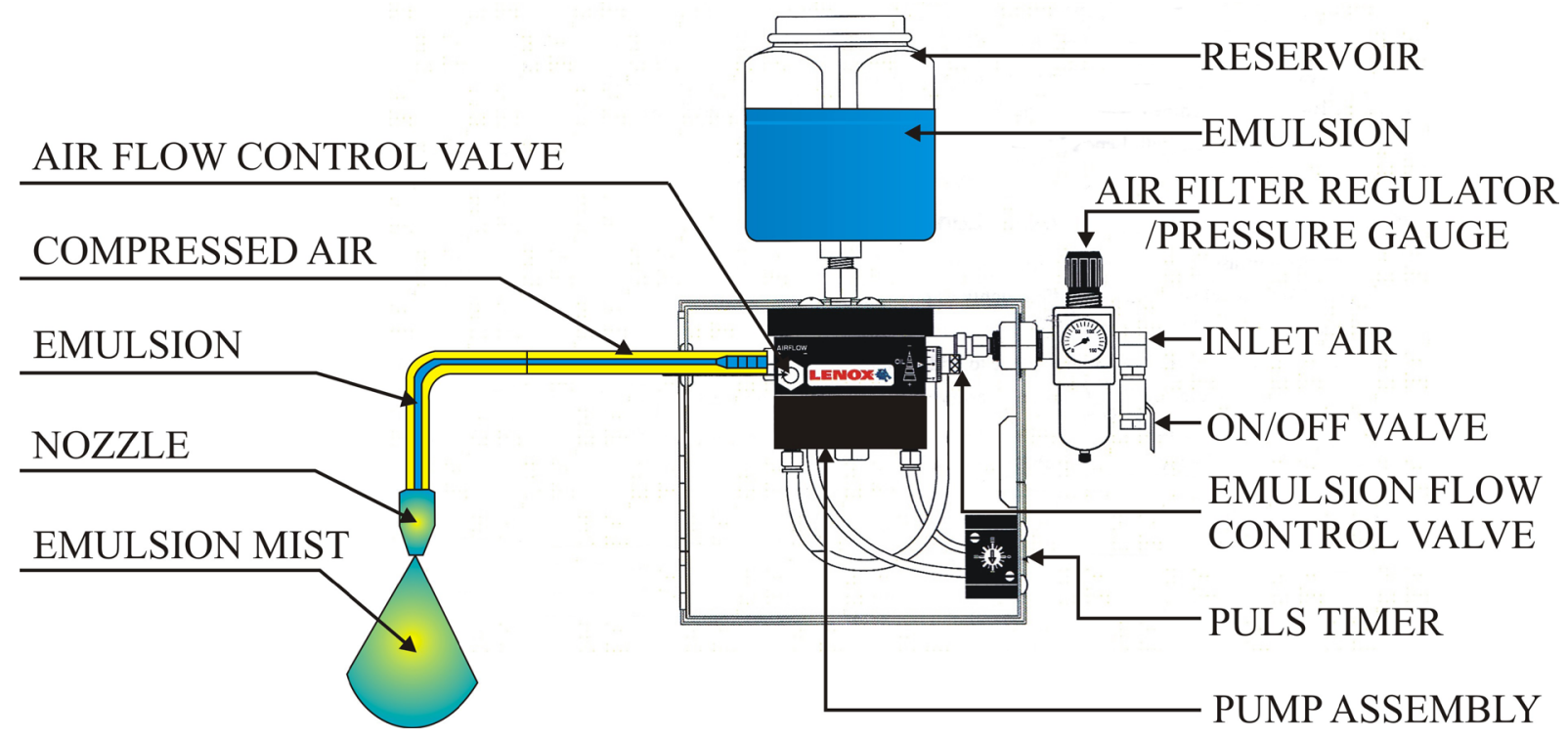

Fig. 1. The principal scheme of Lenox Micronizer unit to create emulsion mist

chining fluids), one can ensure the desired values of the machined surface roughness. Cooling and lubrication fluids are used in cutting processes to improve the tribological properties of the processes which always occur on the contact surface between the tool point and the machined object. Different methods for introducing fluids into contact zone can be used, particularly the minimum quantity cooling lubricant (MQCL) or the minimum quantity lubricant (MQL) methods as an alternative to flood lubricating system $[6,7,12]$. To compensate low cooling ability, i.e. to dissipate larger amounts of heat from the cutting zone, instead of oil, water based emulsion can be used, which is the main active medium in the MQCL method [7]. It was found that MQCL method causes the reduction of the machined surface roughness [9].

In many scientific works, the influence of the parameters of oil or emulsion mist formation on the total surface wettability, i.e. on the number and diameter of droplets supplied to the cutting zone, has been investigated $[5,8$, 13]. It was found that, in the MQL method, the most important parameters influencing the conditions of oil mist formation is the air pressure $[5,13]$. That is why the authors have attempted to find out how the parameters of emulsion mist formation in the MQL method influence selected roughness parameters of a machined surface after the process of AISI
1045 steel turning. Hence, the aim of this paper is to present the influence of emulsion mist parameters on the selected surface roughness parameters when finish turning.

\section{MATERIALS AND METHODS}

C45 EN 10083-2:2006 carbon steel (AISI 1045 carbon steel) was tested. This steel is recommended as standard by ISO 3685:1993 [2].

The universal lathe and the cutter with SDBM2020M12 holder and SNUN 120408 inserts were used in the study. The inserts were made of P25 carbide and had the rake angle equal $-8^{\circ}$, flank angle of $8^{\circ}$, major cutting edge angle of $70^{\circ}$, minor cutting edge angle of $20^{\circ}$ and nose radius equal $0.8 \mathrm{~mm}$.

The study was realized with constant cutting depth $\mathrm{a}_{\mathrm{p}}=1 \mathrm{~mm}$ and with feed rate $\mathrm{f}=0.05-0.3 \mathrm{~mm} /$ rev, cutting speed $\mathrm{v}_{\mathrm{c}}=100-300 \mathrm{~m} / \mathrm{min}$.

The active medium in the MQCL method was WEDOLIT K-910 emulsion with 5\% concentration. To create emulsion mist, Lenox Micronizer unit was used, whose scheme is presented in Figure 1. The air working pressure was equal $0.48 \mathrm{MPa}$, mass flow of emulsion $\mathrm{E}=$ $0.024-1.645 \mathrm{~g} / \mathrm{min}$ and compressed air volume flow was equal $\mathrm{P}=1.2-5.8 \mathrm{l} / \mathrm{min}$.

The roughness measurement was made with TR-200 device and next parameters were studied: arithmetic mean deviations of the assessed 

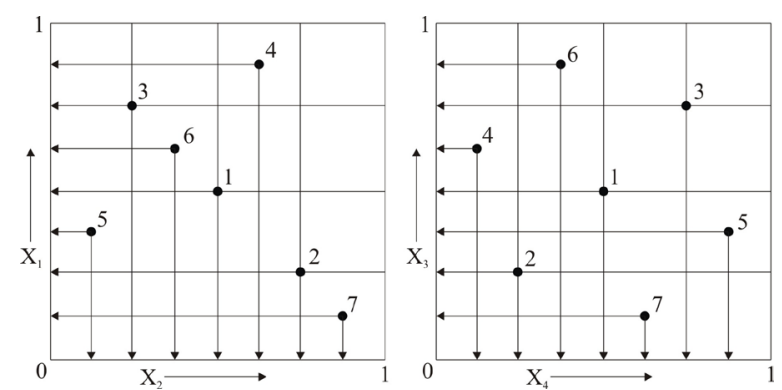

Fig. 2. Design of experiment - projection of the seven examination points on the $\mathrm{X}_{1}-\mathrm{X}_{2}$ and $\mathrm{X}_{2}-\mathrm{X}_{3}$ axes

profile Ra, maximum heights of the assessed profile $\mathrm{Rz}$ and mean widths of profile elements of the assessed profile RSm.

The Parameter Space Investigation (PSI) method [16] was used to define regression equations. The method consists in such situating of experimental points in the multidimensional space that their projections onto $\mathrm{X}_{1}-\mathrm{X}_{2}, \mathrm{X}_{2}-\mathrm{X}_{3}, \ldots$, $\mathrm{X}_{\mathrm{i}}-\mathrm{X}_{\mathrm{j}}$ axes were on equal distances from each other (Fig. 2). Table 1 presents variables of investigation points for PSI method.

Table 1. Coordinates of experimental points for PSI method

\begin{tabular}{|c|c|c|c|c|c|c|c|}
\hline \multirow{2}{*}{ Factors } & \multicolumn{7}{|c|}{ Nr of point } \\
\cline { 2 - 8 } & 1 & 2 & 3 & 4 & 5 & 6 & 7 \\
\hline $\mathrm{X}_{1}$ & 0.8 & 0.4 & 1.21 & 1.42 & 0.62 & 1.02 & 0.2 \\
\hline $\mathrm{X}_{2}$ & 2.9 & 4.9 & 2.4 & 3.9 & 1.2 & 2.4 & 5.9 \\
\hline $\mathrm{X}_{3}$ & 200 & 150 & 250 & 225 & 175 & 300 & 100 \\
\hline $\mathrm{X}_{4}$ & 0.15 & 0.122 & 0.18 & 0.10 & 0.20 & 0.135 & 0.167 \\
\hline
\end{tabular}

a)
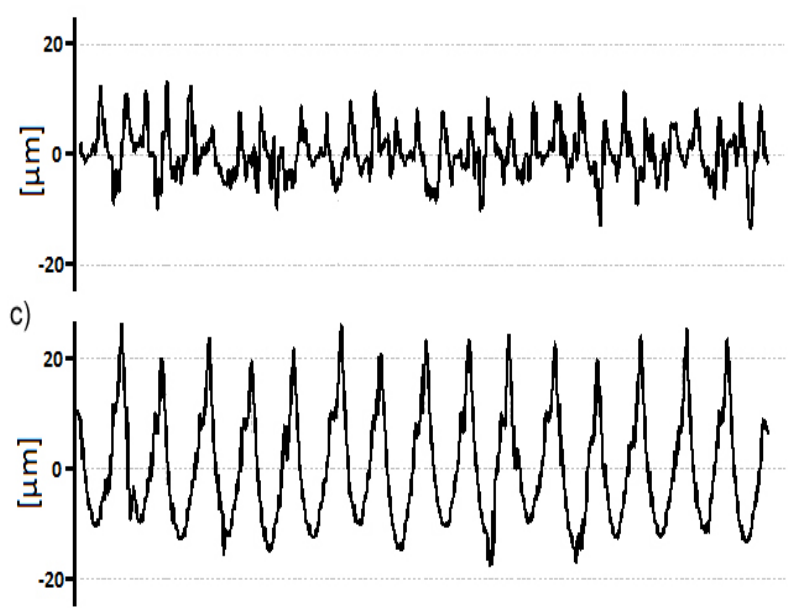

\section{RESULTS AND DISCUSSION}

Figure 3 shows typical surface profilograms AISI 1045 steel elements after finish turning with various feeds and cutting speeds.

The results of the measurements were subjected to statistical treatment, and then multivariate regression equations were obtained:

$$
\begin{aligned}
\mathrm{Ra} & =198 \mathrm{P}^{-0,022 f 1,03} \mathrm{~V}_{\mathrm{c}}^{-0,566}[\mu \mathrm{m}] \\
\mathrm{Rz} & =724 \mathrm{P}^{-0,055 f} 0,583 \mathrm{~V}_{\mathrm{c}}^{-0,659}[\mu \mathrm{m}] \\
\mathrm{RSm} & =1,26 \mathrm{E}^{-0,031} \mathrm{P}^{-0,014 f 1,049}[\mathrm{~mm}]
\end{aligned}
$$

where: E - emulsion flow [g/min],

$$
\begin{aligned}
& \mathrm{P}-\text { air flow }[1 / \mathrm{min}], \\
& f-\text { feed }[\mathrm{mm} / \mathrm{rev}], \\
& \mathrm{v}_{\mathrm{c}} \text { - cutting speed }[\mathrm{m} / \mathrm{min}] .
\end{aligned}
$$

The diagrams of changes of the tested roughness parameters of the machined surface, depending on cutting speed $\mathrm{v}_{\mathrm{c}}$ based on the regression equations are presented in Figure 4. When analyzing diagrams, it can be observed that the effects of cutting speed and feed rate are considerably greater in comparison with emulsion mist parameters.

The PSI method allows probing factor space in order to assess trends in the test parameters changes. Examples of such testing are introduced in Figure 5. It can be seen, when using PSI method the areas of minimal values of tested roughness parameters may be found without any calculating.

Fig. 3. Profile records of machined surfaces: a) $\mathrm{f}=0.1 \mathrm{~mm} / \mathrm{obr} ; \mathrm{v}_{\mathrm{c}}=200 \mathrm{~m} / \mathrm{min}$; b) $\mathrm{f}=0.1 \mathrm{~mm} / \mathrm{rev}$; $\left.\left.\mathrm{v}_{\mathrm{c}}=100 \mathrm{~m} / \mathrm{min} ; \mathrm{c}\right) \mathrm{f}=0.2 \mathrm{~mm} / \mathrm{rev} ; \mathrm{v}_{\mathrm{c}}=200 \mathrm{~m} / \mathrm{min} ; \mathrm{d}\right) \mathrm{f}=0.2 \mathrm{~mm} / \mathrm{rev} ; \mathrm{v}_{\mathrm{c}}=300 \mathrm{~m} / \mathrm{min}$ 

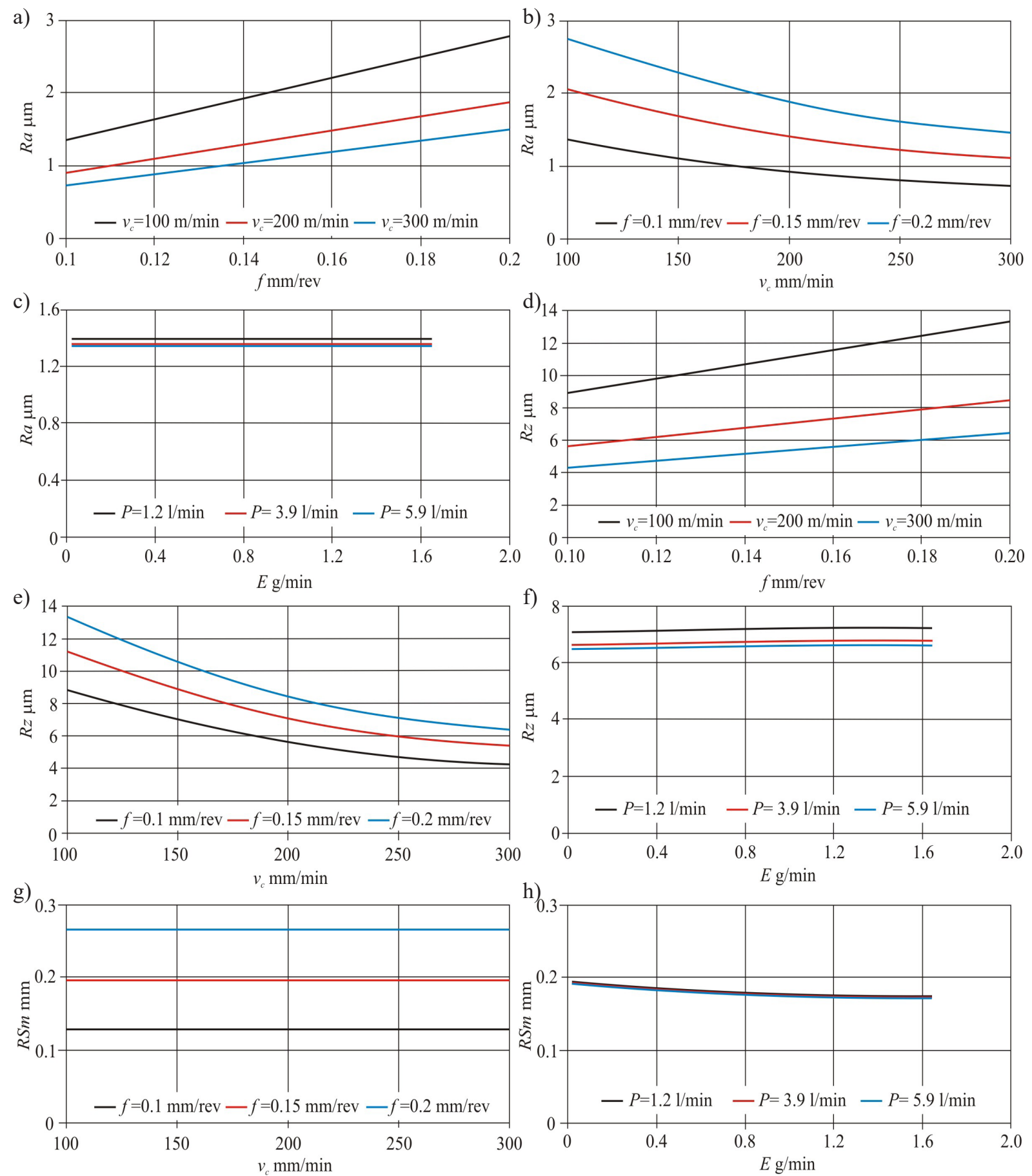

Fig. 4. The impact of turning conditions on surface roughness parameters: a) $\operatorname{Ra}(f), b) \operatorname{Ra}(v c), c) \operatorname{Ra}(E)$, d) $R z(f), e) R z(v c), f) R z(E), g) R S m(v c), h) R S m(E)$

\section{CONCLUSIONS}

The results of testing surface roughness after finishing the turning of AISI1045 carbon steel show that cutting parameters have considerably greater influence on roughness parameters in comparison with emulsion mist conditions. When increasing cutting speed from 100 to $300 \mathrm{~m} / \mathrm{min} \mathrm{Ra}$ and Rz values decrease nearly 2 times but RSm value does not depend on speed. When increasing feed rate from 0.1 to $0.2 \mathrm{~mm} / \mathrm{obr} \mathrm{Ra}, \mathrm{Rz}$ and RSm values increase more than 2 times. The mass emulsion flow does not effect on $\mathrm{Ra}$ and $\mathrm{Rz}$ values, and conversely, if the mass flow rate of the emulsion increases 80 times, RSm value decreases by $15 \%$. Increasing compressed air volume flow about 5 times decrease roughness parameters $2-9 \%$. Parameter Space Investigation method can be used for quick analysis of the tested parameters and optimization of their values. 
a)

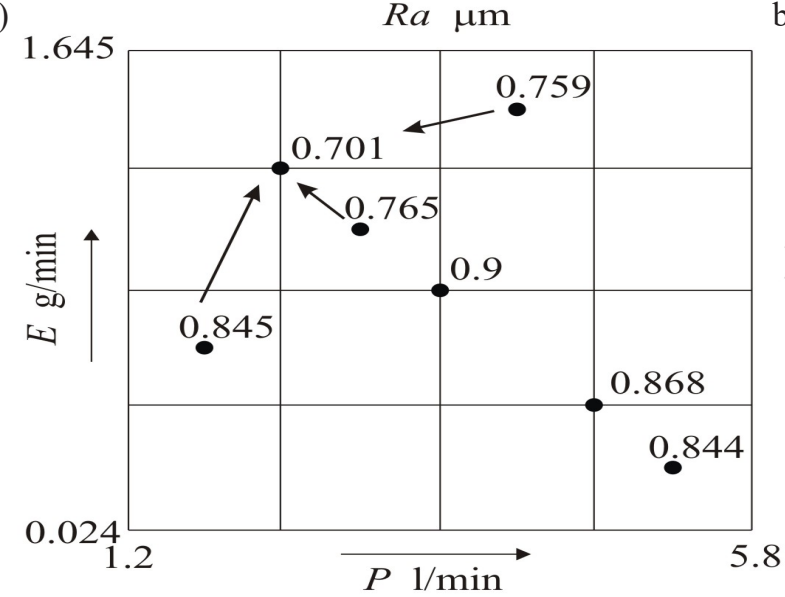

c)

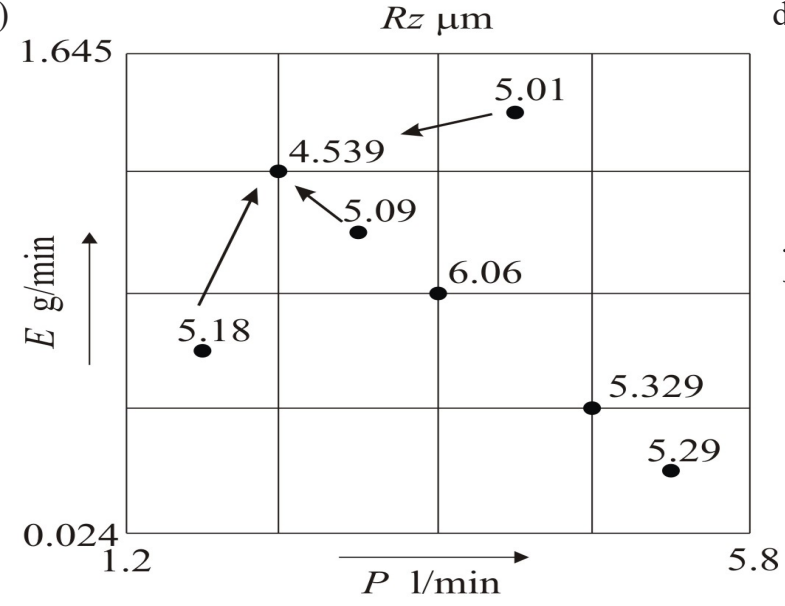

e)

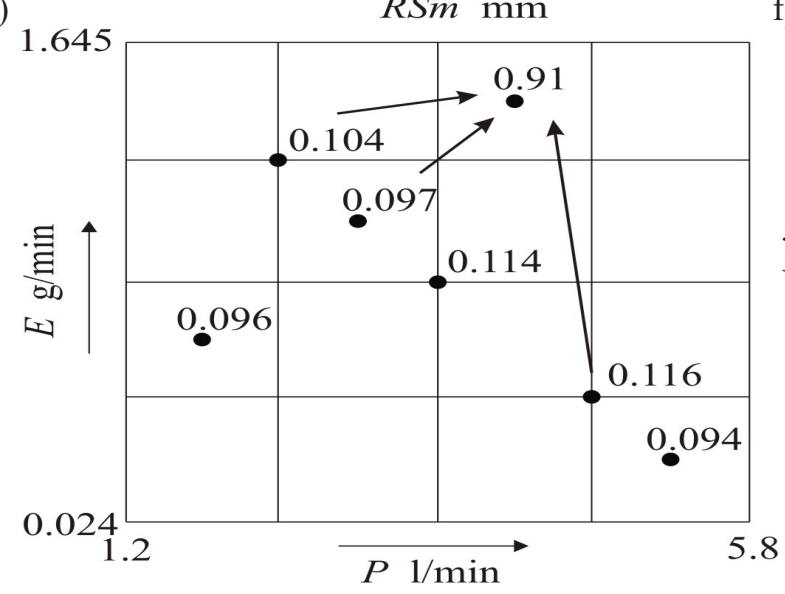

b)

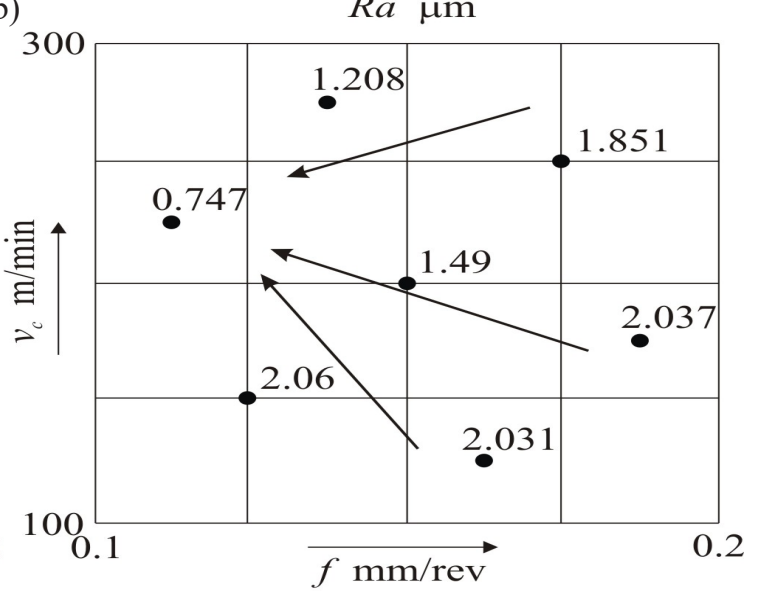

d)

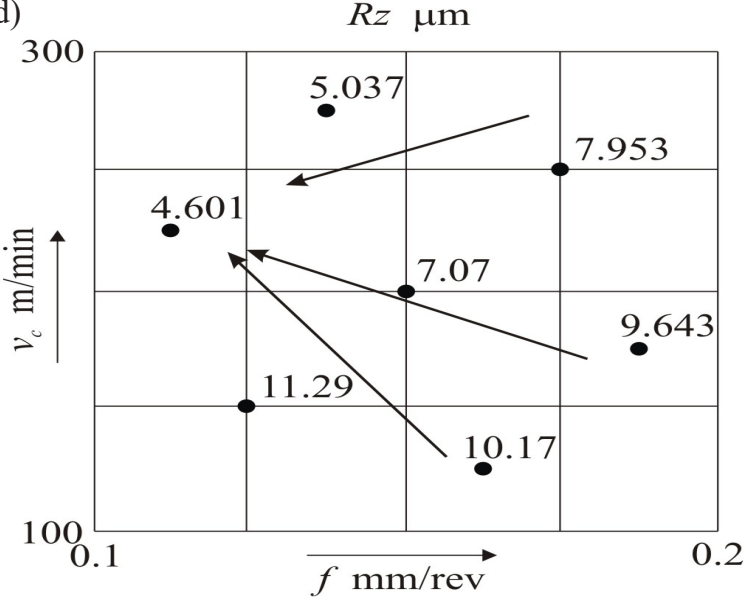

f)

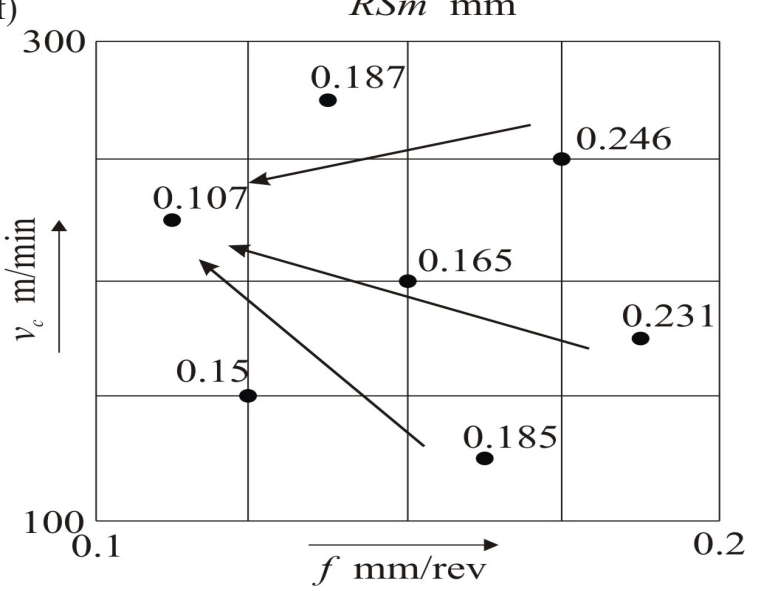

Fig. 5. Some results of probing factor space after finish turning of C45 steel: a) Ra - E(P), b) Ra - vc(f), c) Rz E(P), d) Rz - vc(f), e) RSm - E(P), f) RSmm - vc(f)

\section{REFERENCES}

1. Chang W.R., Hirvonen M., Grönqvist R. The effects of cut-off length on surface roughness parameters and their correlation with transition friction. Safety Science, 42 (8), 2004, 755-769.

2. ISO 3685:1993. Tool-life testing with single-point turning tools.

3. Kubiak K.J., Liskiewicz T.W., Mathia T.G. Surface morphology in engineering applications: Influence of roughness on sliding and wear in dry fretting. Tribology International. 44 (11), 2011, 1427-1432.

4. Legutko S., Nosal S. Kształtowanie technologicznej i eksploatacyjnej warstwy wierzchniej części maszyn. Ośrodek Wydawnictw Naukowych PAN, Poznań, 2004.

5. Maruda R.W., Krolczyk G.M., Feldshtein E., Pusavec F., Szydlowski M., Legutko S., SobczakKupiec A., A study on droplets sizes, their distribution and heat exchange for minimum quantity cool- 
ing lubrication (MQCL). International Journal of Machine Tools and Manufacture, 100, 2016, 81-92.

6. Maruda R.W., Legutko S., Krolczyk G.M., Lukianowicz C., Stoić A., Effect of anti-wear additive on cutting tool and surface layer of workpiece state under MQCL conditions. Tehnicki Vjesnik-Technical Gazette, 22 (5), 2015, 1219-1223.

7. Maruda R.W., Legutko S., Krolczyk G.M., Raos P., Influence of cooling conditions on the machining process under MQCL and MQL conditions. Tehnicki Vjesnik-Technical Gazette, 22 (4), 2015, 965-970.

8. Maruda R.W., Feldshtein E., Legutko S, Królczyk G.M., Research on emulsion mist generation in the conditions of Minimum Quantity Cooling Lubrication (MQCL). Tehnicki Vjesnik-Technical Gazette, 22 (5), 2015, 1213-1218.

9. Maruda R.W., Legutko S., Krolczyk G.M., Hloch S., Michalski M., An influence of active additives on the formation of selected indicators of the condition of the X10CrNi18-8 stainless steel surface layer in MQCL conditions. International Journal of Surface Science and Engineering, 9 (5), 2015, 452-465.

10. Meine K., Schneider T., Spaltmann D., Santner E., The influence of roughness on friction. Part I: The influence of a single step. Wear, 253 (7-8), 2002, 725-732.

11. Meine K., Schneider T., Spaltmann D., Santner E., The influence of roughness on friction. Part II: The influence of multiple steps. Wear, 253 (7-8),
2002, 733-738.

12. Nadolny K., Wojtewicz M., Sienicki W., Herman D., An analysis of centrifugal MQL supply system potential in the internal cylindrical grinding process. Archives of Civil and Mechanical Engineering, 15 (3), 2015, 639-649.

13. Park K.H., Olortegui-Yume J., Yoon M.C., Kwon P., A study on droplets and their distribution for minimum quantity lubrication (MQL). International Journal of Machine Tools and Manufacture. 50 (9), 2010, 824-833.

14. Sing R., Melkote S.N., Hashimoto F., Frictional response of precision finished surfaces in pure sliding. Wear, 258, 2005, 1500-1509.

15. Spijker P., Anciaux G., Molinari J.F., Relations between roughness, temperature and dry sliding friction at the atomic scale. Tribology International, 59, 2013, 222-229.

16. Statnikov R.B., Statnikov A., The Parameter Space Investigation Method Toolkit. Artech House, Boston/London, 2011.

17. Sulima A.M., Šulov B.A., Âgodkin Û.D., Poverhnostnyj sloj i ékspluatacionnye svojstva detalej mašin, Mašinostroenie, Moskva, 1988.

18. Twardowski P., Wojciechowski S., Wieczorowski M., Mathia T.G., Surface roughness analysis of hardened steel after high-speed milling. Scanning, 33 (5), 2011, 386-395. 